\title{
Anthropometric data of adult wheelchair users for Mexican population
}

\author{
Karla Lucero-Duarte ${ }^{\mathrm{a}, *}$, Enrique de la Vega-Bustillos ${ }^{\mathrm{b}}$, Francisco López-Millán ${ }^{\mathrm{a}}$, Selene Soto-Félix ${ }^{\mathrm{b}}$ \\ ${ }^{a}$ Departamento de ingeniería Industrial, Instituto Tecnológico de Hermosillo, Av. Tecnológico S/N, Hermosillo, \\ Sonora, México \\ ${ }^{\mathrm{b}}$ División de Estudios de Posgrado e Investigación, Instituto Tecnológico de Hermosillo, Av. Tecnológico S/N, \\ Hermosillo, Sonora, México
}

\begin{abstract}
The aim of the study was to obtain anthropometric data of adult wheelchair users at Mexico. This study count with 108 disabled people (56 men and 52 women) using the wheelchair and having the upper extremities sufficiently efficient to perform professional activities. The subjects were aged 18-60. From the measurements obtained, it can be said that in each of these measures was observed that men have larger dimensions than women, except for body depth, in which women had a slightly greater difference. When comparing the data in this study against other studies it shows that there is a significant difference between the averages of these studies. Similar results were obtained when comparing our data against data of standard population. Anthropometric data obtained through this study appear to be the only of this kind in Mexico and showed significant differences between measures of disabled persons and standard persons. the use of these data may be helpful for the proper design of workstations designed for use by adults who use.
\end{abstract}

Keywords: Workstation design; Disability; Physical Characteristics comparison

\section{Introduction}

A very useful tool in the design process is the application of anthropometry, which is the science of particular body measurements in order to differentiate between individuals, groups, etc. Anthropometry is the measurement of the dimensions and certain other physical characteristics of the body such as volumes, centers of gravity, inertial properties, mass and body segments.

However, although important, in Mexico practically not carried out studies of this nature and that there were only applied to people without any disability.
That's why the main objective of this study is to develop an anthropometric table for people suffering paraplegia crucial, and this table is intended to serve as the basis for the realization of designs aimed at these people, such as : facilities, work spaces and equipment and this would contribute to progress in integrating these people into our society.

\section{Methods}

\subsection{Subjects}

This study embraced 108 people, 56 men and 52 women, using wheelchair, all in good health and $100 \%$ of upper limb function. The subjects were aged $18-60$, the working age range. In the case of men, the tendency to use the chair, appears more marked among people between 21 and 30 years, with a slightly smaller percentage are people whose ages range between 51 and 60 . People who had a much

\footnotetext{
*Corresponding author. E-mail: kalucero00@hotmail.com
} 
lower rate in the use of the chair were those with 18 to 21 years of age. Regarding women, it found that people who use wheelchairs have from 51 to 60 years, but is percentage is lower than that experienced by men. The second segment was the ages are between 41 to 50 years of age. Finally, as in the case of men, the segment that presented a smaller percentage was the people who are from 18 to 20 years old.

\subsection{Apparatus}

Standard tools for anthropometric measurement, including calipers and anthropometers, were used for length and breadth measurements of various body segments. All apparatus are graduated in millimeters.

\subsection{Procedures}

Based on studies in other countries, has thought of using anthropometric measures suggested by Nowak, E. [1] and Jarosz, E. [2] in their studies in Poland. Fourteen body anthropometric characteristics were measured in the sitting position, and three wheelchair measurement (Table 1). It is important to note that all measurements were made with the wheelchair for each subject and these are different from each other.

\subsection{Calculations}

Body characteristics were determined using arithmetic mean (AVG ), standard deviation (SD), and the values of the $5^{\text {th }}$ and $95^{\text {th }}$ percentile. Table 4 show the results of the six characteristics that, we believe, are the most used for the design of workstations and presents results of other studies made in Mexico with the same data.

\section{Results}

Table 2 summarizes the anthropometric characteristics of the sample by gender. The mean and standard deviation of Sitting height from this sample were $1128.25 \mathrm{~cm}$ and $6.02 \mathrm{~cm}$ for male and 122.65 $\mathrm{cm}$ and $10.45 \mathrm{~cm}$ for female respectively. Table 2 also provides the values of each body dimension at the $5^{\text {th }}$ and $95^{\text {th }}$ percentile. Table 3 show the values for three wheelchair dimensions, armrest height, total length and total width.

\subsection{Comparison with other populations}

Table 4 presents six male anthropometric characteristics. which are compared against three anthropometric studies made in Mexico with people of working age with no physical disabilities. Two studies are presented in the book of R. Avila al [3] and one more in the article by de la Vega et al [4].

By making a comparison of data from current study with data from other populations, it shows that there is a significant difference among data with $\alpha=1 \%$, but with $\alpha=5 \%$ at a level of $5 \%$, the Vertical arm reach to middle finger are equal in the current study and by de la Vega et al [4]

\section{Discussion}

This paper presents 14 measures anthropometric for people using wheelchair and three measures of wheelchair which are essential for the design of a workstations for any industry. Based on the results of the comparisons with other studies with populations of Mexico, we can conclude that workers using a wheelchair are different that people with. Finally, the range and average age of this study, 18 to 60 years and 40.14 years is similar to other studies presented here.

The most important part of anthropometry is its use, pass data to useful information and design workstations that do not put him/her health at risk for injuries caused by extreme reaches, excessive hand forces or reduced space.

\section{References}

[1] Nowak, E. Determination of spatial reach of the arms for workplace design purposes, in: Ergonomics, Taylor \& Francis ed. 1978, pp. 493-507

[2] Jarosz, E. Determination of the workspace of wheelchair users, in: International Journal of Industrial Ergonomic, Elsevier ed. 1996, pp. 123-133

[3] Ávila, R., Prado, L. González, E. Dimensiones antropométricas. Población Latinoamericana. Ed. Universidad de Guadalajara. 2007, pp. 94-123

[4] de la Vega, E. Lucero, K. Lopez, F. Mexican anthropometry of automotive industry workers, in: Human Factors and Ergonomics Society Annual Meeting Proceedings, Industrial Ergonomics, 2010, pp. 1125-1129 


Table 1. Measurement made in body and wheelchair
\begin{tabular}{|l|l|}
\hline Key & Description \\
\hline A & Vertical arm reach to middle finger \\
\hline B & Vertical arm reach with closed hand \\
\hline C & Sitting height \\
\hline D & Eye height \\
\hline E & Shoulder height \\
\hline F & Middle finger height \\
\hline G & Closed hand height \\
\hline H & Front arm reach to middle finger \\
\hline I & Front arm reach with closed hand \\
\hline J & Forearm and hand length \\
\hline K & Forearm and closed hand length \\
\hline L & Lateral arm reach to middle finger \\
\hline M & Lateral arm reach with closed hand \\
\hline N & Chest deep \\
\hline & \\
\hline X & Armrest height \\
\hline Y & Total length \\
\hline Z & Total width \\
\hline
\end{tabular}

Table 2: Anthropometric characteristics of disabled men and women in the sitting positions (in $\mathrm{cm}$ )

\begin{tabular}{|l|l|l|l|l|l|l|l|l|}
\hline & \multicolumn{5}{|c}{ MEN } & \multicolumn{3}{c|}{ WOMEN } \\
\hline & AVG & S.D. & $5 \%$ & $95 \%$ & AVG & S.D. & $5 \%$ & $95 \%$ \\
\hline A & 174.36 & 9.11 & 158.55 & 188.30 & 160.77 & 9.77 & 141.84 & 173.05 \\
\hline B & 164.08 & 9.58 & 146.95 & 176.75 & 150.60 & 9.75 & 132.32 & 163.61 \\
\hline C & 128.25 & 6.02 & 117.28 & 136.45 & 122.65 & 10.45 & 111.04 & 132.12 \\
\hline D & 118.28 & 5.79 & 106.83 & 126.35 & 111.34 & 6.94 & 99.58 & 119.86 \\
\hline E & 102.64 & 5.25 & 93.10 & 110.43 & 97.82 & 5.98 & 89.18 & 105.43 \\
\hline F & 75.96 & 5.83 & 68.25 & 85.68 & 66.50 & 5.13 & 59.14 & 74.81 \\
\hline G & 66.30 & 5.53 & 58.73 & 76.15 & 57.61 & 5.17 & 49.64 & 65.46 \\
\hline H & 89.33 & 5.47 & 80.73 & 98.10 & 81.22 & 4.34 & 74.76 & 88.96 \\
\hline I & 79.59 & 5.19 & 71.30 & 87.93 & 72.25 & 4.59 & 65.66 & 79.69 \\
\hline J & 38.56 & 7.78 & 27.45 & 51.33 & 30.60 & 7.17 & 21.61 & 43.32 \\
\hline K & 29.93 & 9.68 & 19.40 & 41.30 & 22.24 & 7.46 & 13.00 & 34.79 \\
\hline L & 89.30 & 5.32 & 81.08 & 97.13 & 81.12 & 5.45 & 72.26 & 88.91 \\
\hline M & 79.93 & 5.15 & 70.80 & 88.03 & 72.65 & 5.71 & 62.92 & 80.74 \\
\hline N & 35.33 & 4.81 & 27.33 & 43.28 & 36.43 & 6.60 & 28.06 & 48.59 \\
\hline
\end{tabular}

Table 3: characteristics of wheelchairs (in $\mathrm{cm}$ )

\begin{tabular}{|l|r|r|r|r|}
\hline & Average & S. D. & $5 \%$ & $95 \%$ \\
\hline $\mathrm{X}$ & 71.68 & 5.05 & 62.04 & 77.75 \\
\hline $\mathrm{Y}$ & 99.78 & 7.20 & 86.23 & 109.60 \\
\hline $\mathrm{Z}$ & 64.61 & 4.96 & 57.66 & 73.10 \\
\hline
\end{tabular}

Table 4. Comparison among male in the current study with other populations

\begin{tabular}{|c|c|c|c|c|c|c|c|c|}
\hline Dimension & $\begin{array}{l}\text { Current study } \\
\mathrm{n}=56 \\
\text { (Mean) }\end{array}$ & S.D. & $\begin{array}{l}\text { Guadalajara, } \\
\text { Avila } \\
\mathrm{n}=396 \\
\text { (Mean) }\end{array}$ & S.D. & $\begin{array}{l}\text { Guadalajara, } \\
\text { Sanchez } \\
\mathrm{n}=974 \\
\text { (Mean) }\end{array}$ & S.D. & $\begin{array}{l}\text { de la } \\
\text { Vega } \\
n=1072\end{array}$ & S.D \\
\hline Vertical arm reach to mid- & 174.36 & 9.11 & & & & & $\begin{array}{r}176.6 \\
4\end{array}$ & $\begin{array}{r}6.3 \\
2\end{array}$ \\
\hline Vertical arm reach with & 164.08 & 9.58 & & & & & 166.8 & 6.1 \\
\hline closed hand & & & & & & & 2 & 2 \\
\hline Sitting height & 128.25 & 6.02 & & & 124.469 & 4.484 & & \\
\hline Eye height & 118.28 & 5.79 & & & 114.539 & 4.749 & & \\
\hline Shoulder height & 102.64 & 5.25 & & & 97.623 & 4.314 & & \\
\hline $\begin{array}{r}\text { Lateral arm reach with } \\
\text { closed hand }\end{array}$ & 79.93 & 5.14 & 70.9 & 8.15 & & & & \\
\hline
\end{tabular}

